\title{
Chromosomal Arrangement of AHL-Driven Quorum Sensing Circuits in Pseudomonas
}

\author{
Zsolt Gelencsér, ${ }^{1}$ Borisz Galbáts, ${ }^{1,2}$ Juan F. Gonzalez, ${ }^{3}$ K. Sonal Choudhary, ${ }^{4}$ \\ Sanjarbek Hudaiberdiev, ${ }^{4}$ Vittorio Venturi, ${ }^{3}$ and Sándor Pongor ${ }^{4}$ \\ ${ }^{1}$ Faculty of Information Technology, Pázmány Péter Catholic University, Práter u. 50/a, 1083 Budapest, Hungary \\ ${ }^{2}$ Bioinformatics Group, Biological Research Center, Temesvári krt 62, 6726 Szeged, Hungary \\ ${ }^{3}$ Microbiology Group, International Centre for Genetic Engineering and Biotechnology (ICGEB), Padriciano 99, 32149 Trieste, Italy \\ ${ }^{4}$ Protein Structure and Bioinformatics Group, International Centre for Genetic Engineering and Biotechnology (ICGEB), \\ Padriciano 99, 32149 Trieste, Italy
}

Correspondence should be addressed to Vittorio Venturi, venturi@icgeb.org and Sándor Pongor, pongor@icgeb.org

Received 26 October 2011; Accepted 16 November 2011

Academic Editors: A. Hamood, S. Heeb, and S. Matthijs

Copyright ( 2012 Zsolt Gelencsér et al. This is an open access article distributed under the Creative Commons Attribution License, which permits unrestricted use, distribution, and reproduction in any medium, provided the original work is properly cited.

\begin{abstract}
Pseudomonas spp. are able to colonize a large variety of environments due to their wide adaptability which is also associated with an $\mathrm{N}$-acyl homoserine lactone (AHL) gene regulation mechanism called quorum sensing (QS). In this article we present a systematic overview of the genomic arrangement patterns of quorum sensing genes found in Pseudomonas and compare the topologies with those found in other bacterial genomes. We find that the topological arrangement of QS genes is more variable than previously thought but there are a few unifying features that occur in many of the topological arrangements. We hypothesize that the negative regulators of QS that are often found between the canonical $l u x R /$ and $l u x I$-family genes may be crucial for stabilizing the output of QS circuits.
\end{abstract}

\section{Introduction}

Fluorescent Pseudomonas spp. are able to colonize highly dynamic environments such as soil, water, plants, as well as animals, including humans. This wide adaptability is associated with their resourceful metabolic potential and their ability to control gene expression via regulatory elements highly represented in their large genomes. For example, the opportunistic human pathogen Pseudomonas aeruginosa is a notorious member of this genus and is extensively studied for its ability to cause chronic human opportunistic infections in immunocompromised patients [1]. In addition to human pathogens, also important plant pathogens are present in this group of bacteria; Pseudomonas syringae is an important model of plant pathogenic bacteria since its pathovars can infect many different plants (c.f. http://www.pseudomonassyringae.org/). Plant-growth-promoting fluorescent pseudomonads are also studied for their ability to colonize plant-related niches, like the rhizosphere (e.g., P. fluorescens, P. Putida, and P. chlororaphis), where they can act as plant beneficial bacteria either by antagonizing plant deleterious microorganisms or by directly influencing plant disease resistance and growth [2].

Bacteria often possess a regulatory system, known as quorum sensing $(\mathrm{QS})$, to modulate gene expression as a function of their cell density (for reviews see $[3,4]$ ). In Gram negative bacteria, the most common QS system is regulated by the $N$ acyl homoserine lactone signaling molecules (AHLs). Studies of the mechanisms and role of QS in several Pseudomonas spp. indicated that the most common signal molecules used are in fact AHLs [5]. These signals were first described in the marine bioluminescent bacterium Vibrio fischeri in which QS regulates light production (reviewed by [6]). The model $N$-AHL QS system consists of two proteins belonging to the LuxI and LuxR families, respectively, [4, 7]. LuxIfamily proteins are cytoplasmic enzymes responsible for AHL synthesis [8]. AHLs are synthesized from S-adenosyl methionine, which provides the homoserine lactone moiety, and acyl carrier protein, which provides the fatty acyl moiety. After synthesis, the signal can move freely across the bacterial 
membranes and accumulates both intra- and extracellularly in proportion to cell density. Above a critical threshold concentration or cell density, AHLs interact directly with the LuxR-family protein, which in most cases results in the formation of homodimers. These complexes can then bind at specific sequences called lux-boxes that are located in the promoter region of target QS-regulated genes, affecting their expression.

Many important phenotypes are regulated by AHL QS and QS has been suggested as a possible target to control bacterial colonization [9]. QS regulates phenotypes related to both pathogenesis (virulence associated factors like toxins, motility, secreted enzymes, and biofilm-related genes/proteins) and to beneficial effects in plant growth promoting rhizobacteria (PGPR) (e.g., production of antibiotic and antifungal compounds and induction of systemic resistance in the plant [10-13]).

AHL QS is particularly interesting in the pseudomonads due to the presence, diversity, and complexity of regulatory circuits present in various species. In the case of $P$. aeruginosa, AHL QS seems conserved and ubiquitous, being composed of a complex hierarchy of two LuxI/R pairs and a series of regulators $[5,14]$. In fact, it has been estimated that quorum sensing regulates up to $3 \%$ of $P$. aeruginosa genes. On the other hand, most strains of $P$. fluorescens and $P$. putida do not possess an AHL QS system $[15,16]$. In this study, we performed an in-depth systematic study on the chromosomal arrangement and synteny of AHL QS systems in pseudomonads in order to determine the commonalities and differences that may exist between pseudomonads and other bacteria. Previous studies concentrated either on the presence or absence of AHL QS genes in bacteria [17], or on the regulatory design principles of selected QS systems [18, 19]. Here, we present a survey of AHL-driven QS circuits in pseudomonads and compare the chromosomal arrangements with those found in other bacterial genomes.

\section{QS Genes in Complete Bacterial Genomes}

We used the sequence data of 1346 full bacterial proteomes found at the NCBI bacterial genome repository as well as published QS operon sequences from NCBI GenBank (data last accessed on June 12, 2011). Draft genome sequences were excluded from the analysis because of the uncertain annotations we found in some of them. The search included standard bioinformatics methodologies and manual curation (see supplementary materials available online at doi: 10.5402/2012/484176). We started our search for luxR sensor/regulators, luxI AHL synthases, rsaL, and rsaM repressor homologues in complete bacterial genomes and included only a set of selected examples of Pseudomonas data from incomplete genomes (Tables 1 and 2). For $l u x R, l u x I$, $r s a L$, and rsaM we use the symbols $R, I, L$, and $M$, respectively, and refer to them as "QS genes". Solo $R$ genes [20] as well as other lonely occurrences of QS genes were not considered. This cautious approach of manual curation was adopted because we were primarily interested in the genomic arrangements and not so much in finding hitherto unannotated genes in the complete genomes. Still we found a few unannotated genes that were accepted on the condition that they were in one of the previously observed topological arrangements. From a total of over 4.3 million genes analyzed, we found $624 R$ genes (29 unannotated), $269 \mathrm{I}$ genes (12 unannotated), $39 \mathrm{~L}$ genes (11 unannotated), and $36 \mathrm{M}$ genes (36 unannotated). Out of the 1346 complete genomes, 143 were found to contain QS genes in the vicinity of other QS genes (i.e., within a distance of $3000 \mathrm{nt}$ ). All of these were proteobacterial genomes. We do not consider our analysis as comprehensive because, among other things, it was based on the reading frames given in the genome annotations, and we left Rhizobia and Agrobacterium species out of the survey because the arrangement of their QS genes is different from Pseudomonas. We found a few conflicts with respect to the gene functions assigned in the genome annotations but not in Pseudomonas.

\section{Genomic Topologies of AHL-Driven QS Circuits}

We found two major types of topological arrangements that we term $R I$ and $R X I$, respectively, (Tables 1 and 2). In RI, the two genes are vicinal while in $R X I$ there is at least one additional gene between the two $\operatorname{LuxI}$ and $L u x R$ family genes.

3.1. The RI Topology. There are 3 possible variations, namely tandem (unidirectional), convergent, divergent. All of these are found in proteobacteria, Pseudomonas does not seem to contain the divergent topology which can, however, be found in other gamma proteobacteria.

3.2. The RXI Topology. In these topologies, one or more genes are found between the $R$ and the $I$ genes. All the 8 possible arrangements are found in proteobacteria, however, only 3 in Pseudomonas where the $X$ gene is most frequently $L$ (RsaL, found in P. aeruginosa, P. putida, and P. fuscovaginae species). $M$ is much more frequently found in Burkholderia, the only Pseudomonas to contain $M$ is $P$. fuscovaginae, which is at the same time, the only pseudomonad found so far to contain both $L$ and $M$ genes. Both the $L$ and the $M$ genes have their canonical topologies which are shown in the table separately, denoted as RLI (L1) and RMI (M1), respectively. Both of these topologies can be found both in Burkholderia and in Pseudomonas. However, some Burkholderia species contain an additional copy of $M$, which is in a non-canonical arrangement, either because there are one to five additional genes betweem $R$ and $M$ (M2 topology, found in B. pseudomallei 1106a, B. pseudomallei 1710b, B. pseudomallei 668, B. pseudomallei K96243, B. thailandensis E264), or because the otherwise constitutive $R$ gene is missing in the immediate vicinity of the MI tandem (M3 topology, B. ambipharia AMMD, and MC40-6). On the other hand, P. fluorescens NCIMB 10586 contains a gene coding for an enzyme, mupX in the X position [21].

\section{The X Genes}

In Pseudomonas, the genes in the $\mathrm{X}$ position are predominantly negative regulators of the QS response. RsaL $(L)$ [22] 
TABLE 1: Typical chromosomal arrangements of AHL-driven quorum sensing circuits in Pseudomonas.

\begin{tabular}{|c|c|c|c|c|c|c|}
\hline \multirow{2}{*}{ ID } & \multirow{2}{*}{ Gene topology } & \multirow{2}{*}{$\begin{array}{l}\text { Occurrence in } \\
\text { Pseudomonas }\end{array}$} & \multicolumn{4}{|c|}{ Occurrence in other Proteobacteria } \\
\hline & & & Alfa & Beta & Gamma & Delta \\
\hline \multicolumn{7}{|c|}{ "RI" patterns ${ }^{* *}$} \\
\hline$R 1$ & $\mathrm{R}$ & $\begin{array}{l}\text { P. aeruginosa } \mathrm{LESB} 58 \\
\text { P. aeruginosa } \mathrm{PA7} \\
\text { P. aeruginosa } \mathrm{PAO} 1 \\
\text { P. aeruginosa UCBPP-PA14 }\end{array}$ & 64 & 13 & 11 & 0 \\
\hline$R 2$ & $\mathrm{R}$ & $\begin{array}{l}\text { P. syringae pv. phaseolicola } \\
1448 \mathrm{~A} \\
\text { P. syringae pv. syringae } \\
\text { B728a } \\
\text { P. syringae pv. tomato str. } \\
\text { DC3000 } \\
\text { P. chlororaphis PCL1391 } \\
\text { P. fluorescens 2-79* }\end{array}$ & 2 & 2 & 48 & 3 \\
\hline$R 3$ & 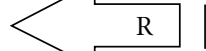 & - & 1 & 3 & 7 & 0 \\
\hline \multicolumn{7}{|c|}{ "RXI" patterns** } \\
\hline$L 1$ & $\mathrm{R}$ & $\begin{array}{l}\text { P. aeruginosa LESB58 } \\
\text { P. aeruginosa } \mathrm{PA7} \\
\text { P. aeruginosa } \mathrm{PAO} 1 \\
\text { P. aeruginosa UCBPP-PA14 } \\
\text { P. putida WCS358 } \\
\text { P. putida IsoF*, PCL1445* } \\
\text { P. fuscovaginae UPB0736 }\end{array}$ & 0 & 7 & 8 & 0 \\
\hline$M 1$ & $R$ & P. fuscovaginae UPB0736 & 0 & 20 & 10 & 0 \\
\hline$X 1$ & $\mathrm{R}$ & P. fluorescens NCIMB 10586 & 0 & 0 & 1 & 0 \\
\hline
\end{tabular}

* Pattern does not contain the overlap indicated.

$* * R I$ patterns $=$ two genes are in vicinity and $R X I$ patterns $=$ one additional gene is between luxR and LuxI.

was shown to belong to the tetrahelical superclass of $\mathrm{H}-\mathrm{T}-\mathrm{H}$ proteins [23]. Members of this family are widespread repressors in bacteria and bind to DNA as dimers. We found that homologues of RsaL frequently occur outside QS circuits in various bacterial genomes (data not shown). In P. fuscovaginae, RsaL binds to DNA next to the lux box and prevents expression of the $R$ gene [24]. In contrast, RsaM $(M)$ is a protein of unknown structure that seems to occur only in the context of QS circuits. $M$ was found to negatively regulate QS in P. fuscovaginae [24]. Finally, mupX of $P$. fluorescens NCIMB10586 is an amidase-hydrolase that was shown to degrade the AHL signal produced by the same species thereby decreasing the QS response [21].

\section{Overlapping Genes}

Two topologies, R2 and L1, contain overlaps at the proximal ends of convergent genes. Such overlaps are not uncommon in tightly coregulated gene circuits of bacteria [25], for instance restriction modification systems [26]. The R2 type of arrangements in $P$. syringae contain overlapping $R$ and
$I$ genes (2-to $68 \mathrm{nt}$ ) while $P$. fluorescens genomes do not. In the $L 1$ type QS circuits of $P$. aeruginosa, the overlaps are $10 \mathrm{nt}$ while in P. fuscovaginae the overlap is $20 \mathrm{nt}$. On the contrary, the $L 1$ circuits of $P$. putida are not overlapping, though the open reading frames of $R$ and $L$ are only $4 \mathrm{nt}$ apart. Tsai and Winans noted that the overlapping $R 2$-like arrangement is common to QS circuits in which $R$ proteins are able to fold, dimerize, bind DNA, and regulate transcription in the absence of AHLs; moreover, these proteins are antagonized by their cognate AHLs [27]. The same authors also argued that the expression of one member of a convergent and overlapping gene pair might be antagonized by the expression of the other member, either via RNA polymerase collisions or by hybridization of the two complementary $m R N A s$ [27].

\section{Regulatory Implications}

The most conspicuous feature of the various circuit topologies is the potential negative regulatory effect of $R$ on $I$ which, as mentioned above, goes in parallel with the well known 
TABle 2: Examples of Pseudomonas species with of AHL-driven quorum sensing networks.

\begin{tabular}{|c|c|c|}
\hline Pseudomonas species & QS circuit & $\begin{array}{c}\text { Pattern id } \\
\text { (from Table 1) }\end{array}$ \\
\hline \multirow{2}{*}{$\begin{array}{l}\text { P. aeruginosa LESB58 } \\
{[28]}\end{array}$} & $\mathrm{rhlR} / \mathrm{rhlI}$ & $\mathrm{R} 1$ \\
\hline & lasR/rsaL/lasI & L1 \\
\hline \multirow{2}{*}{ P. aeruginosa PA7 [29] } & $\mathrm{rhlR/rhlI}$ & $\mathrm{R} 1$ \\
\hline & lasR/rsaL/lasI & $\mathrm{L} 1$ \\
\hline \multirow{2}{*}{ P. aeruginosa PAO1 [30] } & rhlR/rhlI & $\mathrm{R} 1$ \\
\hline & lasR/rsaL/lasI & L1 \\
\hline \multirow{2}{*}{$\begin{array}{l}\text { P. aeruginosa } \\
\text { UCBPP-PA14 [31] }\end{array}$} & rhlR/rhlI & $\mathrm{R} 1$ \\
\hline & lasR/rsaL/lasI & $\mathrm{L} 1$ \\
\hline \multirow{2}{*}{$\begin{array}{l}\text { P. fuscovaginae UPB } 0736 \\
{[24]}\end{array}$} & $\mathrm{sR} / \mathrm{rsaM} / \mathrm{sI}$ & M1 \\
\hline & $\mathrm{vR} / \mathrm{rsaL} / \mathrm{vI}$ & $\mathrm{L} 1$ \\
\hline $\begin{array}{l}\text { P. syringae pv. } \\
\text { phaseolicola 1448A [32] }\end{array}$ & AhlR/AhlI & $\mathrm{R} 2$ \\
\hline $\begin{array}{l}\text { P. syringae pv. syringae } \\
\text { B728a [33] }\end{array}$ & Psyr_1622/Psyr_1621 & $\mathrm{R} 2$ \\
\hline $\begin{array}{l}\text { P. syringae pv. tomato str. } \\
\text { DC3000 [34] }\end{array}$ & psyR/psyI & $\mathrm{R} 2$ \\
\hline $\begin{array}{l}\text { P. chlororaphis PCL1391 } \\
{[35,36]}\end{array}$ & phzR/PhzI & $\mathrm{R} 2$ \\
\hline P. fluorescens 2-79 [37] & $\mathrm{phzR} / \mathrm{PhzI}$ & $\mathrm{R} 2$ \\
\hline $\begin{array}{l}\text { P. fluorescens NCIMB } \\
10586[38]\end{array}$ & mupR/mupX/mupI & $\mathrm{X} 1$ \\
\hline P. putida WCS358 [39] & $\mathrm{uR} / \mathrm{rsaL} / \mathrm{uI}$ & L1 \\
\hline P. putida IsoF [40] & ppuR/rsaL/ppuI & L1 \\
\hline P. putida PCL1445 [11] & ppuR/rsaL/ppuI & L1 \\
\hline
\end{tabular}

positive regulatory effect. In other words, $R$ seems both to activate and to inhibit the $I$ genes in a number of cases. In $R X I$ circuits, $R$ activates an $X$ gene that decreases the effect of $I$. In the $R 2$ circuits, the negative effect follows from the overlap between the convergently transcribed $R$ and $I$ genes [27]. Regulatory circuits in which an element can both activate and inhibit another element are termed incoherent feed forward loops or IFFLs [41, 42]. In contrast to simple feed forward arrangements, IFFLs can exhibit a number of complex behavior patterns (for a review see [43]). Perhaps the most important of these is the stabilization of the output signals: while simple feed forward circuits have no inherent limits on their output, IFFL networks have bounded output which ensures robustness against fluctuations in the input signal levels. Most often, QS regulatory circuits are simply referred to as autoinduction loops which, at least in theory, should increase their output without limits. The examples shown in this survey suggest that a stabilizing, negative regulatory pathway is present in many QS systems. It was found experimentally that deletion of RsaL or RsaM leads to a dramatic increase in AHL production, but the resulting mutants are less virulent than the wild type [24], which shows, on the other hand, that the negative regulatory path may in fact be a crucial stabilizing element within the QS circuits.
Finally, we mention that the chromosomal arrangements found in QS genes seem more varied than expected so the search for common regulatory principles remains an important task for future research.

\section{Acknowledgments}

Z. Gelencsér and B. Galbáts are Ph.D. and undergraduate students, respectively, at the Faculty of Information Technology, Pázmány Péter Catholic University, Budapest. J. F. Gonzalez, S. Hudaiberdiev, and K. S. Choudhary are Ph.D. students at ICGEB, Trieste. Work at the Szeged Biological Center was supported by OTKA Grant K. 84335.

\section{References}

[1] B. W. Holloway and A. F. Morgan, "Genome organization in Pseudomonas," Annual Review of Microbiology, vol. 40, pp. 79105, 1986.

[2] D. J. O'Sullivan and F. O'Gara, “Traits of fluorescent Pseudomonas spp. involved in suppression of plant root pathogens," Microbiological Reviews, vol. 56, no. 4, pp. 662-676, 1992.

[3] A. Camilli and B. L. Bassler, "Bacterial small-molecule signaling pathways," Science, vol. 311, no. 5764, pp. 1113-1116, 2006.

[4] C. Fuqua, M. R. Parsek, and E. P. Greenberg, "Regulation of gene expression by cell-to-cell communication: acyl-homoserine lactone quorum sensing," Annual Review of Genetics, vol. 35, pp. 439-468, 2001.

[5] V. Venturi, "Regulation of quorum sensing in Pseudomonas," FEMS Microbiology Reviews, vol. 30, no. 2, pp. 274-291, 2006.

[6] E. G. Ruby, "Lessons from a cooperative, bacterial-animal association: the Vibrio fischeri-Euprymna scolopes light organ symbiosis," Annual Review of Microbiology, vol. 50, pp. 591624, 1996.

[7] N. A. Whitehead, A. M. L. Barnard, H. Slater, N. J. L. Simpson, and G. P. C. Salmond, "Quorum-sensing in Gram-negative bacteria," FEMS Microbiology Reviews, vol. 25, no. 4, pp. 365404, 2001.

[8] K. M. Pappas, C. L. Weingart, and S. C. Winans, "Chemical communication in proteobacteria: biochemical and structural studies of signal synthases and receptors required for intercellular signalling," Molecular Microbiology, vol. 53, no. 3, pp. 755-769, 2004.

[9] T. B. Rasmussen, M. E. Skindersoe, T. Bjarnsholt et al., "Identity and effects of quorum-sensing inhibitors produced by Penicillium species," Microbiology, vol. 151, no. 5, pp. 13251340, 2005.

[10] T. F. C. Chin-A-Woeng, D. Van Den Broek, B. J. J. Lugtenberg, and G. V. Bloemberg, "The Pseudomonas chlororaphis PCL1391 sigma regulator psrA represses the production of the antifungal metabolite phenazine-1-carboxamide," Molecular Plant-Microbe Interactions, vol. 18, no. 3, pp. 244-253, 2005.

[11] J. F. Dubern, B. J. J. Lugtenberg, and G. V. Bloemberg, "The ppuI-rsaL-ppuR quorum-sensing system regulates biofilm formation of Pseudomonas putida PCL1445 by controlling biosynthesis of the cyclic lipopeptides putisolvins I and II," Journal of Bacteriology, vol. 188, no. 8, pp. 2898-2906, 2006. 
[12] G. Girard, E. T. van Rij, B. J. J. Lugtenberg, and G. V. Bloemberg, "Regulatory roles of psrA and rpoS in phenazine-1-carboxamide synthesis by Pseudomonas chlororaphis PCL1391," Microbiology, vol. 152, no. 1, pp. 43-58, 2006.

[13] R. Schuhegger, A. Ihring, S. Gantner et al., "Induction of systemic resistance in tomato by $\mathrm{N}$-acyl-L-homoserine lactoneproducing rhizosphere bacteria," Plant, Cell and Environment, vol. 29, no. 5, pp. 909-918, 2006.

[14] M. Schuster and E. P. Greenberg, "A network of networks: quorum-sensing gene regulation in Pseudomonas aeruginosa," International Journal of Medical Microbiology, vol. 296, no. 2-3, pp. 73-81, 2006.

[15] M. Elasri, S. Delorme, P. Lemanceau et al., "Acyl-homoserine lactone production is more common among plant-associated Pseudomonas spp. than among soilborne Pseudomonas spp," Applied and Environmental Microbiology, vol. 67, no. 3, pp. 1198-1209, 2001.

[16] L. Steindler, I. Bertani, L. De Sordi, J. Bigirimana, and V. Venturi, "The presence, type and role of N-acyl homoserine lactone quorum sensing in fluorescent Pseudomonas originally isolated from rice rhizospheres are unpredictable," FEMS Microbiology Letters, vol. 288, no. 1, pp. 102-111, 2008.

[17] R. J. Case, M. Labbate, and S. Kjelleberg, "AHL-driven quorum-sensing circuits: their frequency and function among the Proteobacteria," ISME Journal, vol. 2, no. 4, pp. 345-349, 2008.

[18] A. B. Goryachev, "Design principles of the bacterial quorum sensing gene networks," Wiley Interdisciplinary Reviews, vol. 1, no. 1, pp. 45-60, 2009.

[19] A. B. Goryachev, "Understanding bacterial cell-cell communication with computational modeling," Chemical Reviews, vol. 111, no. 1, pp. 238-250, 2011.

[20] S. Subramoni and V. Venturi, "LuxR-family "solos": bachelor sensors/regulators of signalling molecules," Microbiology, vol. 155, no. 5, pp. 1377-1385, 2009.

[21] J. Hothersall, A. C. Murphy, Z. Iqbal et al., "Manipulation of quorum sensing regulation in Pseudomonas fluorescens NCIMB 10586 to increase mupirocin production," Applied Microbiology and Biotechnology, vol. 90, no. 3, pp. 1017-1026, 2011.

[22] T. De Kievit, P. C. Seed, J. Nezezon, L. Passador, and B. H. Iglewski, "RsaL, a novel repressor of virulence gene expression in Pseudomonas aeruginosa," Journal of Bacteriology, vol. 181, no. 7, pp. 2175-2184, 1999.

[23] G. Rampioni, F. Polticelli, I. Bertani et al., "The Pseudomonas quorum-sensing regulator RsaL belongs to the tetrahelical superclass of H-T-H proteins," Journal of Bacteriology, vol. 189, no. 5, pp. 1922-1930, 2007.

[24] M. Mattiuzzo, I. Bertani, S. Ferluga et al., "The plant pathogen Pseudomonas fuscovaginae contains two conserved quorum sensing systems involved in virulence and negatively regulated by RsaL and the novel regulator RsaM," Environmental Microbiology, vol. 13, no. 1, pp. 145-162, 2011.

[25] D. C. Krakauer, "Stability and evolution of overlapping genes," Evolution, vol. 54, no. 3, pp. 731-739, 2000.

[26] M. K. Kaw and R. M. Blumenthal, "Translational independence between overlapping genes for a restriction endonuclease and its transcriptional regulator," BMC Molecular Biology, vol. 11, article 87, 2010.

[27] C. S. Tsai and S. C. Winans, "LuxR-type quorum-sensing regulators that are detached from common scents," Molecular Microbiology, vol. 77, no. 5, pp. 1072-1082, 2010.
[28] C. Winstanley, M. G. I. Langille, J. L. Fothergill et al., "Newly introduced genomic prophage islands are critical determinants of in vivo competitiveness in the liverpool epidemic strain of Pseudomonas aeruginosa," Genome Research, vol. 19, no. 1, pp. 12-23, 2009.

[29] P. H. Roy, S. G. Tetu, A. Larouche et al., "Complete genome sequence of the multiresistant taxonomic outlier Pseudomonas aeruginosa PA7," PLoS ONE, vol. 5, no. 1, Article ID e8842, 2010.

[30] C. K. Stover, X. Q. Pham, A. L. Erwin et al., "Complete genome sequence of Pseudomonas aeruginosa PAO1, an opportunistic pathogen," Nature, vol. 406, no. 6799, pp. 959-964, 2000.

[31] D. G. Lee, J. M. Urbach, G. Wu et al., "Genomic analysis reveals that Pseudomonas aeruginosa virulence is combinatorial," Genome Biology, vol. 7, no. 10, article R90, 2006.

[32] V. Joardar, M. Lindeberg, R. W. Jackson et al., "Whole-genome sequence analysis of Pseudomonas syringae pv. phaseolicola $1448 \mathrm{~A}$ reveals divergence among pathovars in genes involved in virulence and transposition," Journal of Bacteriology, vol. 187, no. 18, pp. 6488-6498, 2005.

[33] H. Feil, W. S. Feil, P. Chain et al., "Comparison of the complete genome sequences of Pseudomonas syringae pv. syringae B728a and pv. tomato DC3000," Proceedings of the National Academy of Sciences of the United States of America, vol. 102, no. 31, pp. 11064-11069, 2005.

[34] C. R. Buell, V. Joardar, M. Lindeberg et al., "The complete genome sequence of the arabidopsis and tomato pathogen Pseudomonas syringae pv. tomato DC3000," Proceedings of the National Academy of Sciences of the United States of America, vol. 100, no. 18, pp. 10181-10186, 2003.

[35] S. R. Khan, J. Herman, J. Krank et al., "N-(3-hydroxyhexanoyl)-L-homoserine lactone is the biologically relevant quormone that regulates the phz operon of Pseudomonas chlororaphis strain 30-84," Applied and Environmental Microbiology, vol. 73, no. 22, pp. 7443-7455, 2007.

[36] D. W. Wood and L. S. Pierson, "The phzI gene of Pseudomonas aureofaciens 30-84 is responsible for the production of a diffusible signal required for phenazine antibiotic production," Gene, vol. 168, no. 1, pp. 49-53, 1996.

[37] D. V. Mavrodi, V. N. Ksenzenko, R. F. Bonsall, R. J. Cook, A. M. Boronin, and L. S. Thomashow, "A seven-gene locus for synthesis of phenazine-1-carboxylic acid by Pseudomonas fluorescens 2-79," Journal of Bacteriology, vol. 180, no. 9, pp. 2541-2548, 1998.

[38] A. K. El-Sayed, J. Hothersall, S. M. Cooper, E. Stephens, T. J. Simpson, and C. M. Thomas, "Characterization of the mupirocin biosynthesis gene cluster from Pseudomonas fluorescens NCIMB 10586," Chemistry and Biology, vol. 10, no. 5, pp. 419430, 2003.

[39] I. Bertani and V. Venturi, "Regulation of the N-acyl homoserine lactone-dependent quorum-sensing system in rhizosphere Pseudomonas putida WCS358 and cross-talk with the stationary-phase RpoS sigma factor and the global regulator GacA," Applied and Environmental Microbiology, vol. 70, no. 9, pp. 5493-5502, 2004.

[40] A. Steidle, M. Allesen-Holm, K. Riedel et al., "Identification and characterization of an N-acylhomoserine lactone-dependent quorum-sensing system in Pseudomonas putida strain IsoF," Applied and Environmental Microbiology, vol. 68, no. 12, pp. 6371-6382, 2002.

[41] U. Alon, "Network motifs: theory and experimental approaches," Nature Reviews Genetics, vol. 8, no. 6, pp. 450-461, 2007. 
[42] R. Milo, S. Shen-Orr, S. Itzkovitz, N. Kashtan, D. Chklovskii, and U. Alon, "Network motifs: simple building blocks of complex networks," Science, vol. 298, no. 5594, pp. 824-827, 2002.

[43] D. Kim, Y. K. Kwon, and K. H. Cho, "The biphasic behavior of incoherent feed-forward loops in biomolecular regulatory networks," BioEssays, vol. 30, no. 11-12, pp. 1204-1211, 2008. 

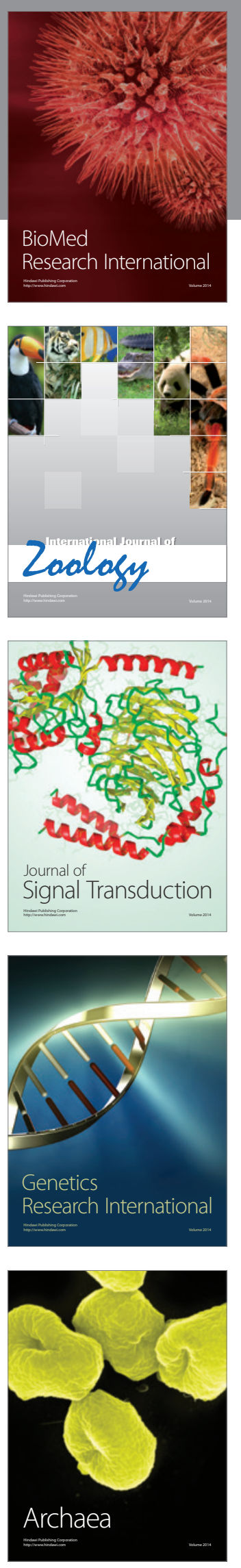
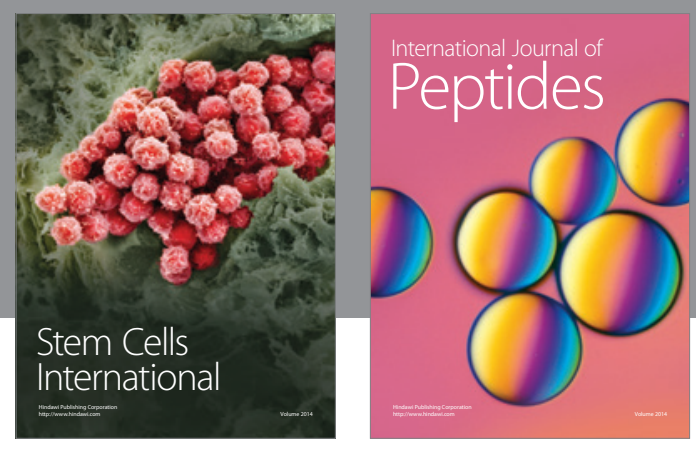

Submit your manuscripts at

http://www.hindawi.com
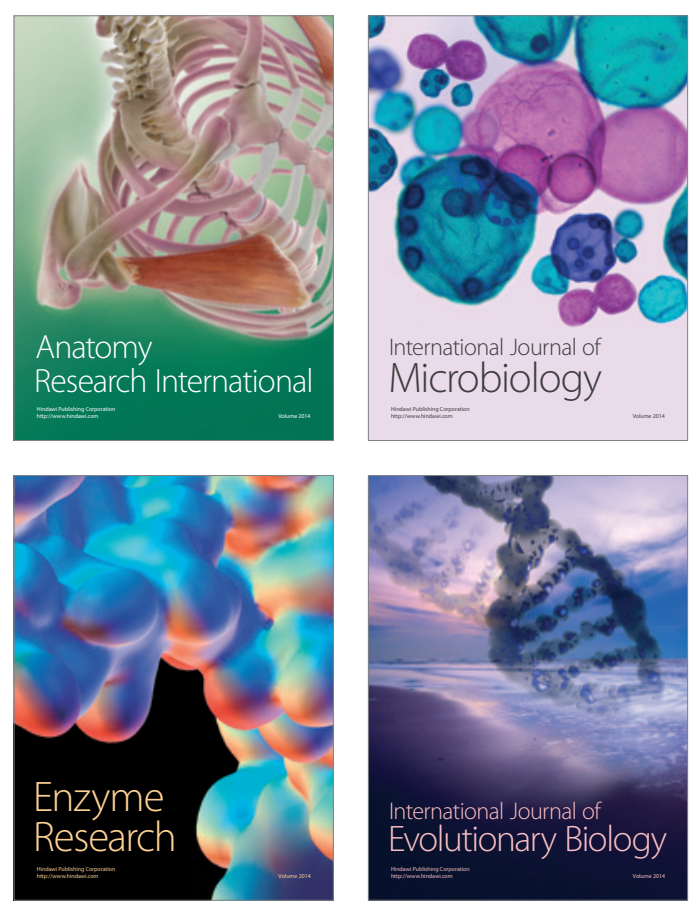
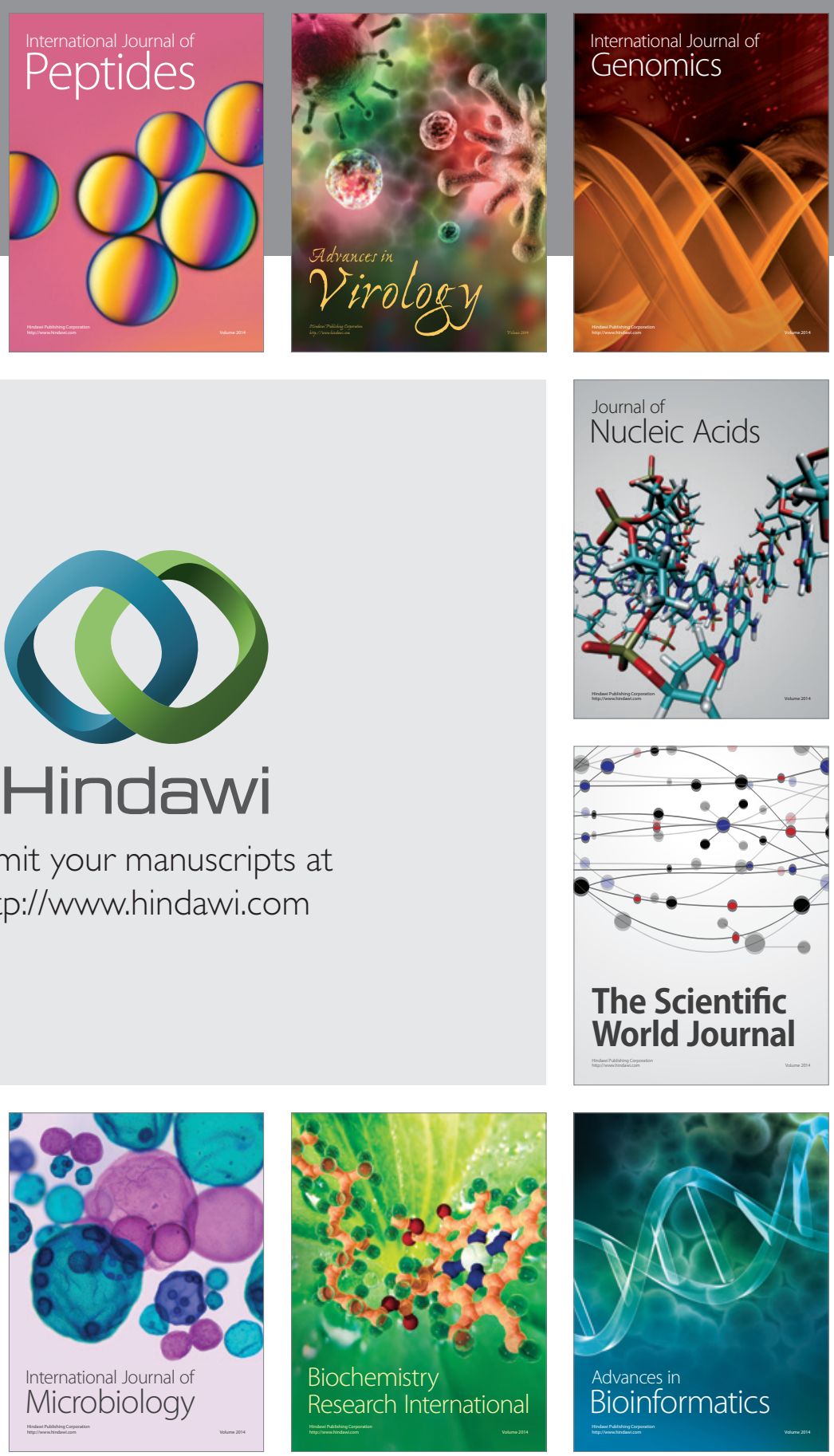

The Scientific World Journal
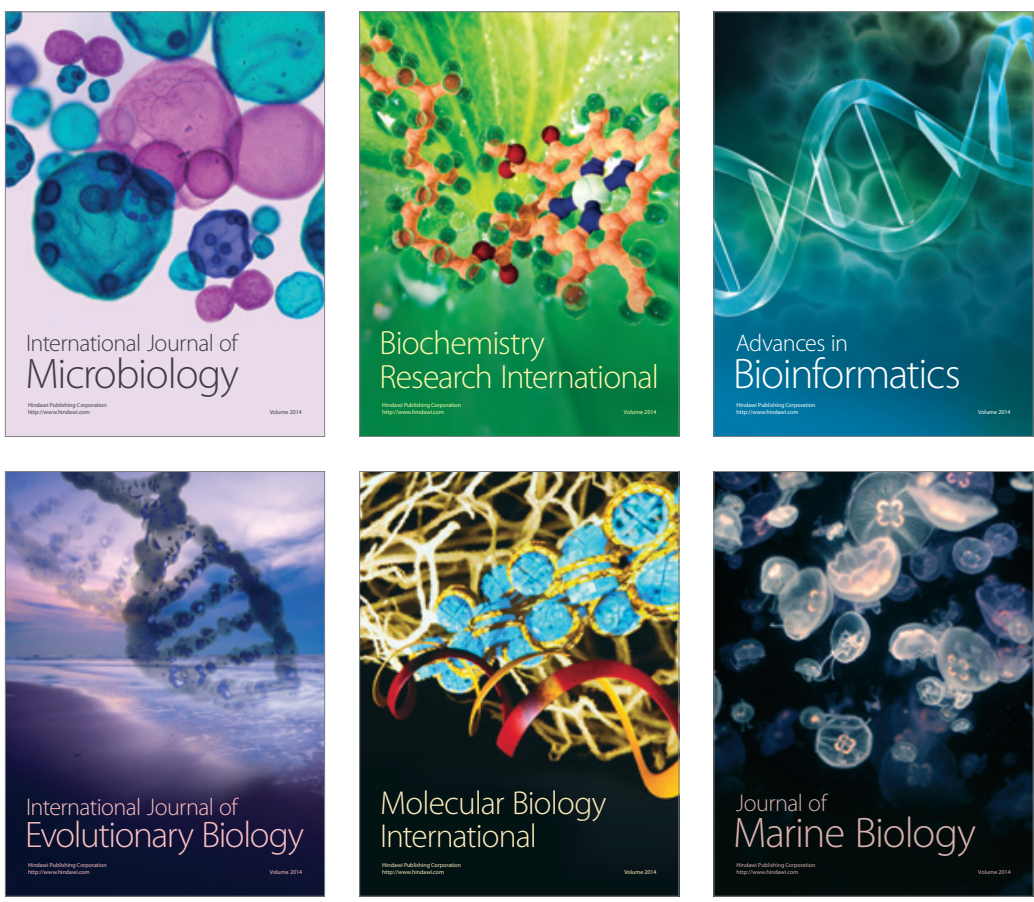